\title{
Patterns in new dimensionless quantities containing melting temperature, and their dependence on pressure
}

\author{
U. WALZER $(*)$
}

Received on March 24th, 1980

\begin{abstract}
The relationships existing between melting temperature and other macroscopic physical quantities are investigated. A new dimensionless quantity $Q_{0}$ not containing the Grüneisen parameter proves to be suited for serving in future studies as a tool for the determination of the melting temperature in the outer core of the Earth. The pressure depen. dence of more general dimensionless quantities $Q_{n}$ is determined analytically and, for the chemical elements, numerically, too. The patterns of various interesting dimensionless quantities are shown in the Periodic Table and compared.
\end{abstract}

\section{ZUSAMMENFASSUNG}

Die Beziehungen der Schmelztemperatur zu anderen makroskopischen physikalischen Meßgrößen wurden untersucht. Eine neuc dimensionslose

(*) Zentralinstitut für Physik der Erde der AdW der DDR, Institutsteil Jena, 69 Jena (DDR) Burgweg 11. 
geeignet, in künftigen Arbeiten als Hilfsmittel für die Bestimmung der Schemelztemperatur im äußeren Kern der Erde zu diernen. Die Druckabhängigkeit noch allgemeinerer dimensionsloser Größen $Q_{n}$ wurde analytisch und für die chemischen Elemente auch numerisch bestimmt. Verschiedene interessante dimensionslose Größen wurden im Periodensystem dargestellt und verglichen.

\section{Riassunto}

Nel presente articolo si investigano le interrelazioni esistenti fra tempcrature di fusione ed altre grandezze fisiche macroscopiche. Si mostra che puó essere consigliata una nuova quantità adimensionale $Q_{o}$, non contenente il parametro di Gruneisen, come strumento di indagine in futuri studi della temperatura di fusione del nucleo terrestre esterno. Viene determinata poi analiticamente e per elementi chimici anche numericamente, la dipendenza dalla pressione di più generali grandezze adimensionali $Q_{n}$. Sono inoltre mostrate e confrontate le caratteristiche degli andamenti di varie interressanti quantità ademensionali nel sistema periodico.

\section{INTRODUCTION}

It is the objective of this study to approximately express the melting temperature $T_{m}$ of elements and anorganic chemical compounds as a function of other physical quantities. The specific requirements are that (I), to permit an application in future studies, we endeavour to use only such quantities that are reliably known also for the outer core of the Earth from modern seismological and other geophysical models (e.g., after Dziewonski et al. 1975) and (II) the relationship is to be valid at least for high pressures ranging between 1354 and 3289 kbars $(1 \mathrm{kbar}=100 \mathrm{MPa})$.

We start the search for this relationship in the normal pressure range. The starting point is a paper by Plendl (1974) from which Fig. 1 has been taken. $Z_{a}$ is the atomic coordination valency which is defined as the product of the atomic valence in the elemental state and the ratio of the first order atomic coordinations of two successive polymorphs. $C_{\text {str }}$ is the structural parameter, $C^{-1}$ str is proportional to the density of 
paching of the atoms $C^{-1}{ }_{s i r}$ is also proportional to the number of significant approaches of adjacent oscillating atoms. If we compare Fig. 1 with Fig. 2, we find that although there is an indication of the anticipated proportionality $T_{m} \sim Z_{a} \cdot C_{s t r}$, but scattering unfortunately is considerably greater than given by Plendl. According to Plendl and Gielisse $(1969,1970)$, there is also a proportionality between bulk modulus $x$ and $Z_{a} \cdot C_{s t r}$. Consequently, we may also expect a proportionality between melting temperture and bulk modulus. To verify this, we plot the melting temperature data of the elements after Gschneidner (1964) versus the bulk modulus for zero pressure after the data collected

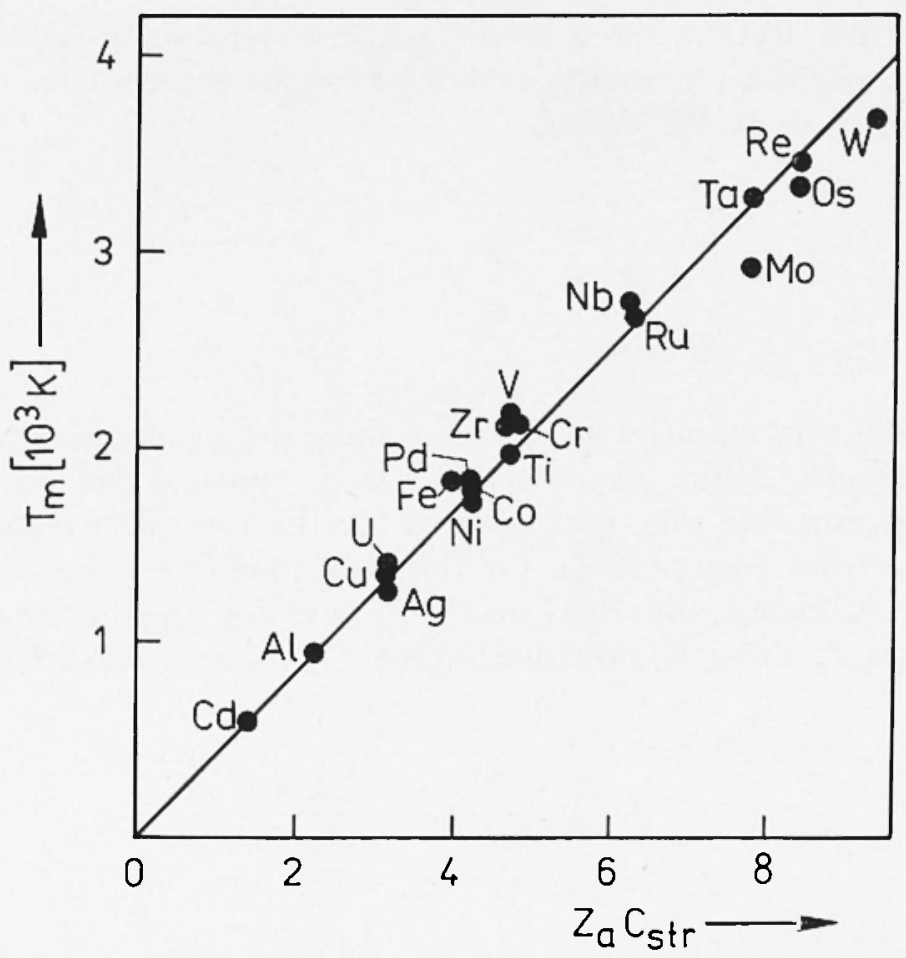

Fig. 1 - Linear relationship between the experimental data of the melting point $\left(\mathrm{T}_{\mathrm{m}}\right)$ and the atomic data of $\left(\mathrm{Z}_{\mathrm{a}} \mathrm{C}_{\mathrm{str}}\right)$ for 20 metallic elements with strong bondings (Figure and caption after Plendl, 1974). 
by Ullmann and Pan'kov (1976) (see Fig. 3). The coordination numbers in the diagram are designated by symbols. There is, in fact, an indication of proportionality. But scattering is so great here, too, that it is hardly suited for practical purposes. If, however, we form in section 3 dimensionless quantities as few material-dependent as possible, we can assume from Fig. 3 that it must contain the quotient $T_{m} / \%$.

2. COMPARISON OF A FEW DIMENSIONLESS QUANTITIES FOR ZERO PRESSURE

In this section, let us form a few dimensionless quantities for the chemical elements and study their correlations at the pressure $P=0$. We define

$$
N_{1}=\frac{F}{R_{u}} \cdot \frac{\varkappa}{T_{m} \rho}
$$

and plot this quantity in Fig. 4 versus the group numbers of the Periodic Table. $R_{v}=8.31441 \mathrm{~J} /(\mathrm{K} \cdot \mathrm{mol})$ is the universal gas constant. We take the numbers for the formula weight $F$ in $\mathrm{kg} / \mathrm{mol}$ from Ebert (1976), for the bulk modulus $x$ and density p from Ullmann and Pan'kov (1976) and for the melting temperature $T_{m}$ from Gschneidner (1964). Moreover, we define

$$
N_{2}=\frac{F}{R_{0}} \cdot \frac{3 x_{1} x}{\rho}
$$

and plot this quantity, too, in the Periodic Table (see Fig. 5), using the linear coefficient of thermal expansion $\alpha_{l}$, the atomic volume $F / \rho$ and density $\rho$ from Geschneidner (1964). According to Gschneidner (1964) the product $\alpha T_{m}=0.0186 \pm 0.0080$ is nearly 


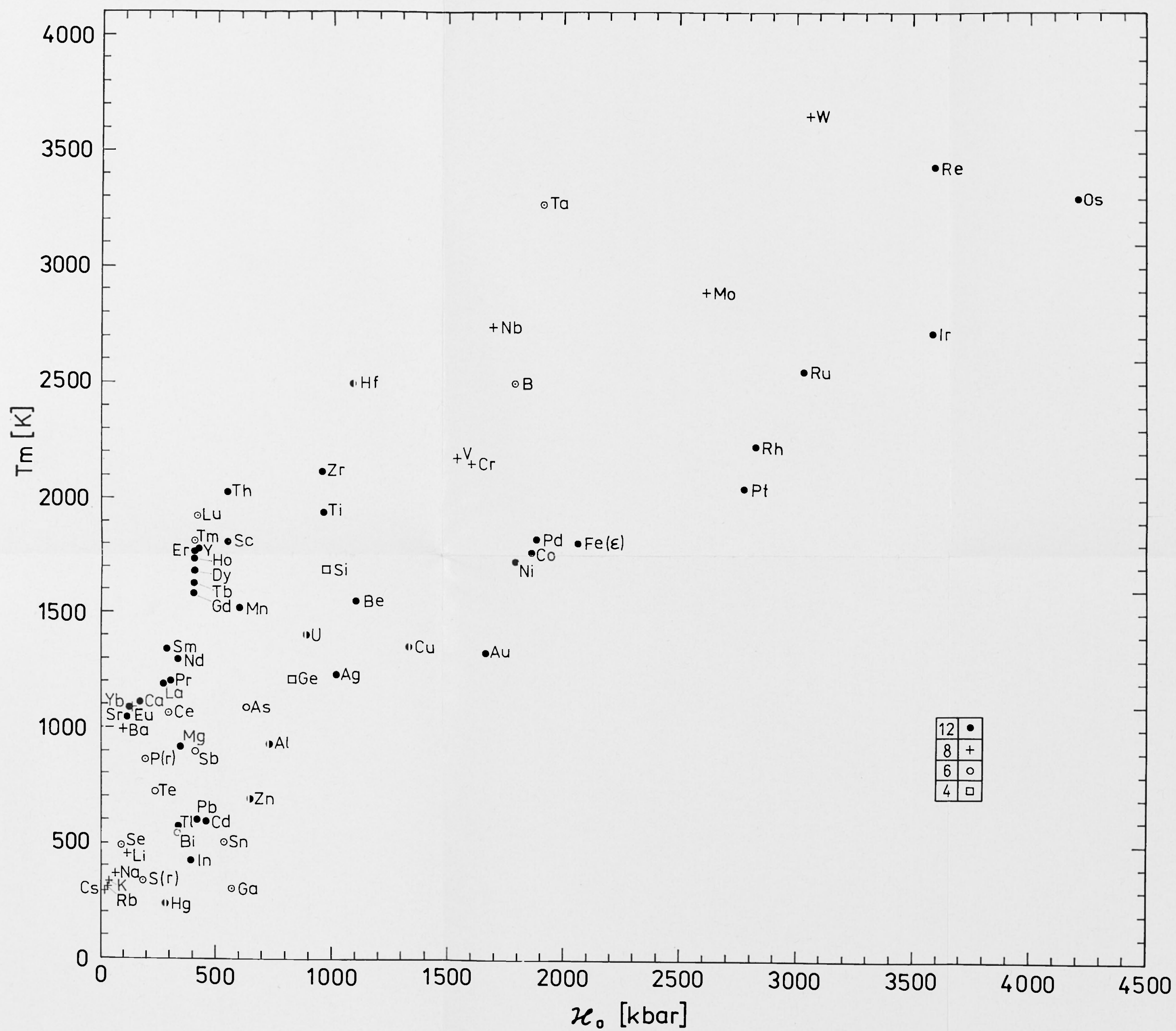

Fig. 3 - Melting temperature $T_{m}$ versus bulk modulus for zero pressure $x_{0}$. The legend shows the assignment between symbols and coordination number. 


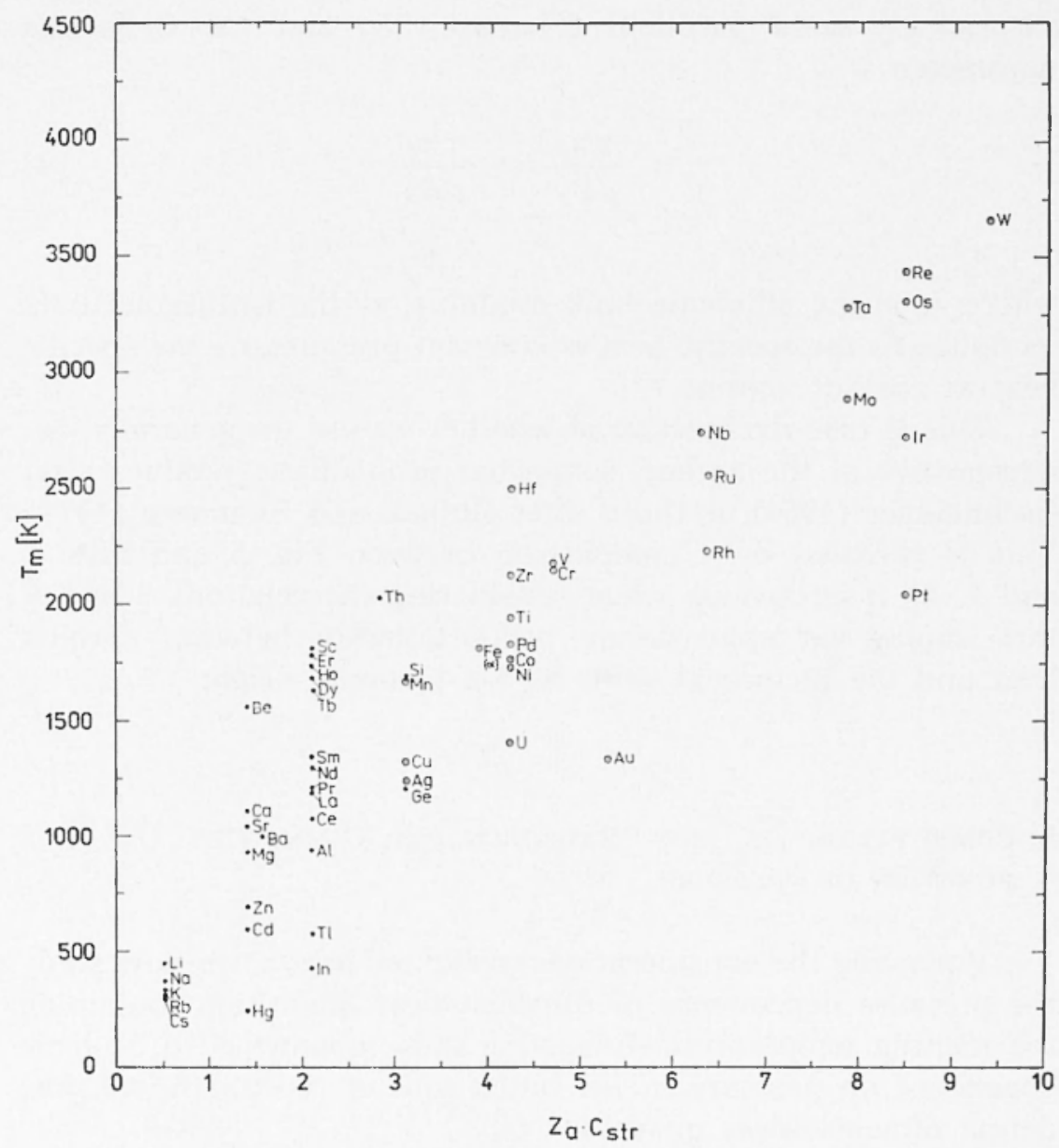

Fig. 2 - Melting temperature $T_{m}$, after values given by Gsehneidner (1964) versus the atomic data $Z_{a} C_{s t r}$, after given by Plendl and Gielisse (1972), plotted by the author. Elements with strong bondings, i. e., elements for which $Z_{a} \geq 9 / 2$, are marked by an encircled point. Attention was given to the correct assignement of the phases.

constant for all elements, $\alpha$ being the coeffincient of thermal expansion. However, the parallelism between the curves in Figs. 4 and 5 is not as good as expected. Incidentally, there is a 
surprisingly good parallelism between $N_{2}$ and the Grineisen parameter

$$
\gamma=\frac{\alpha x_{S}}{\rho C_{P}}=\frac{\alpha \varkappa_{T}}{\rho C_{V}},
$$

where $x_{S}$ is the adiabatic bulk modulus, $x_{T}$ the isothermal bulk modulus, $C_{P}$ the specific heat at constant pressure, $C_{V}$ the specific heat at costant volume.

This is true irrespective of whether we use the generally, i.e., irrespective of the author, somewhat problematic $\gamma$-values after Gschneidner (1964) or those after Guinan and Steinberg (1974). This is revealed by a comparison between Fig. 5 and Figs. 6 and 7. As it is obvious when considering the relations 2 and 3 , this implies an approximate proportionality between specific heat and the reciprocal value of the formula weight.

3. Computation of NeW Dimensionless Quantities $Q_{n}$ as a FUNCTION OF PRESSURE

Following the considerations presented above, we now study the pressure dependence of dimensionless quantities containing the melting temperature. Expecting these quantities to be little dependent on pressure in the outer core of the Earth, we now define dimensionless quantities $Q_{n}$

$$
Q_{n}=N_{1}^{-1} \gamma^{n}
$$

$n$ being a real number. A look at formulas [1] and [4] shows that, if a certain $Q_{n}$ in the outer core of the Earth is known as a function of depth, the quotient $T_{m} / F$ can be determined, when $\rho, \varkappa$ and $\gamma$ are taken from seismological models of the Earth. $T_{m}$ is the melting temperature and $F$ the formula weight. The problematic Grüneisen parameter $\gamma$ (see discussion by Anderson 


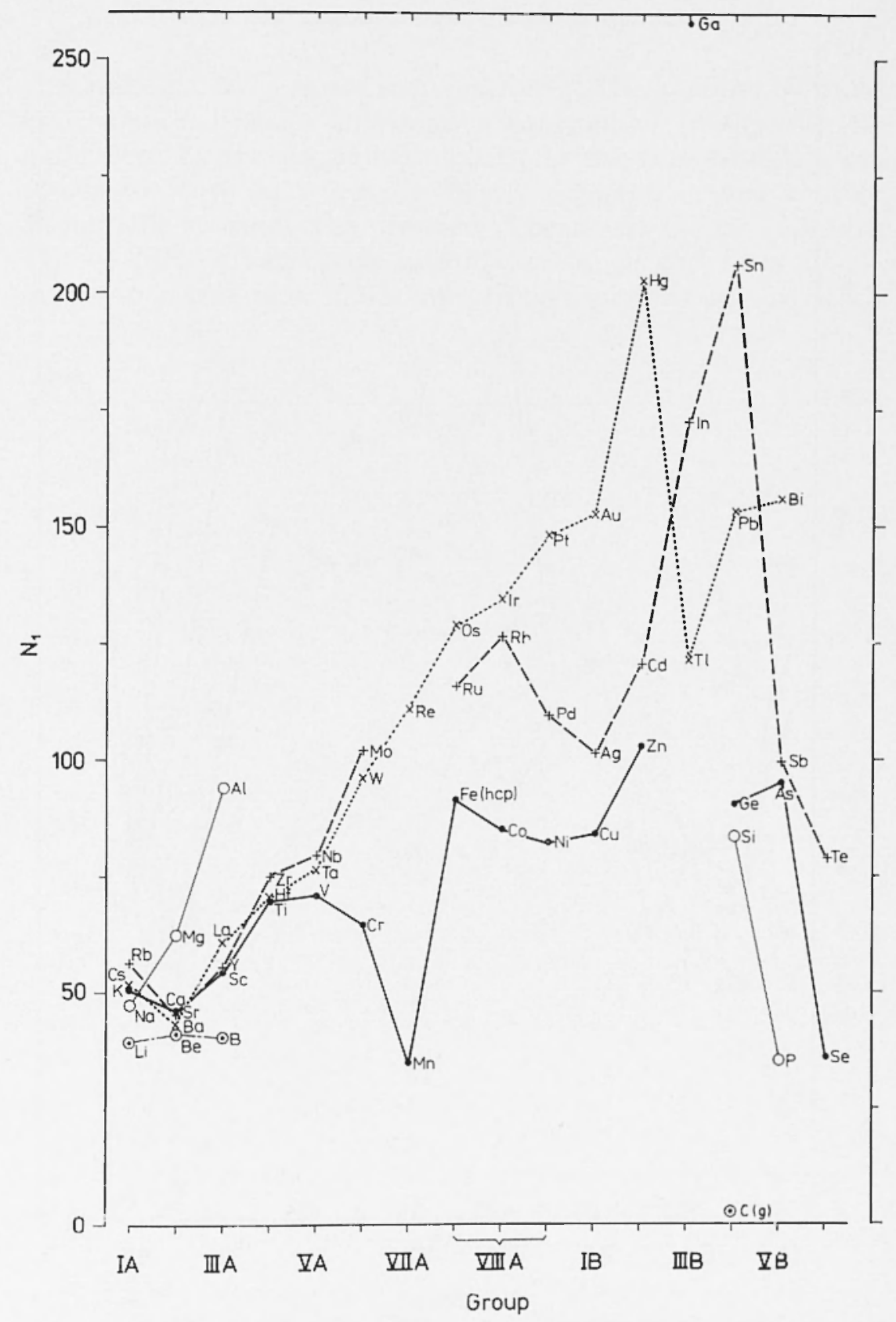

Fig. 4 - The dimensionless quantity $N_{1}$, defined by Eq. [1], of the elements of the second, third, fourth, fifth and sixth periods of the Periodic Table. 


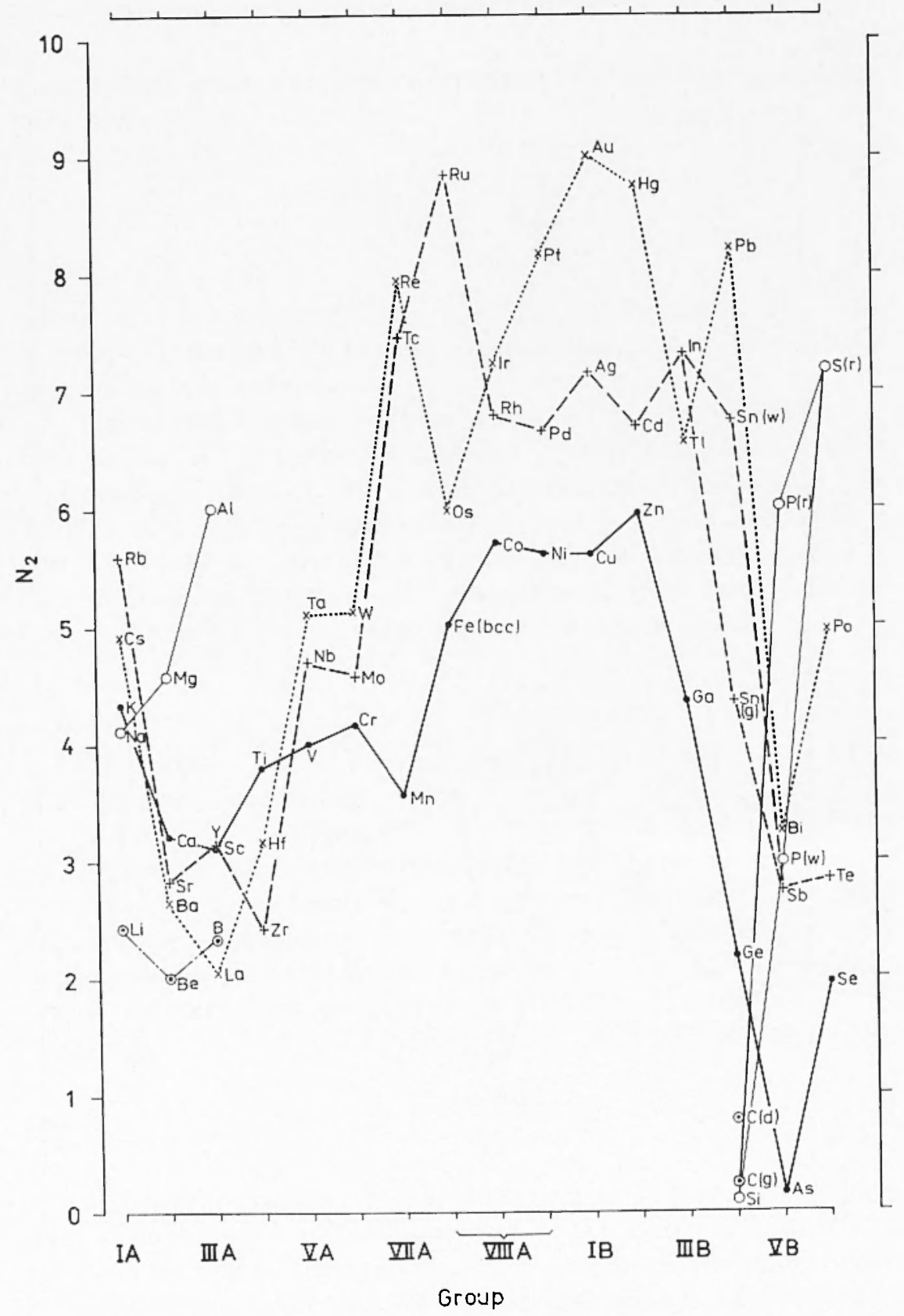

Fig. 5 - The dimensionless quantity $\mathrm{N}_{2}$, defined by Eq. [2], of the elements of the second, third, fourth, fifth and sixth periods of the Periodic Table. 
and Mulargia 1977), is not required for $Q_{o}$. The quantity $Q_{n}$ could, for instance, become known as a function of pressure in the outer core by the possibility that $Q_{n}$ of the core-candidate materials for core pressures lie closely adjacent to one another. To be able to study the pressure dependence of the quantities $Q_{n}$, we have to make an assumption as to the form of the interatomic potential. It has already been pointed out by Boschi

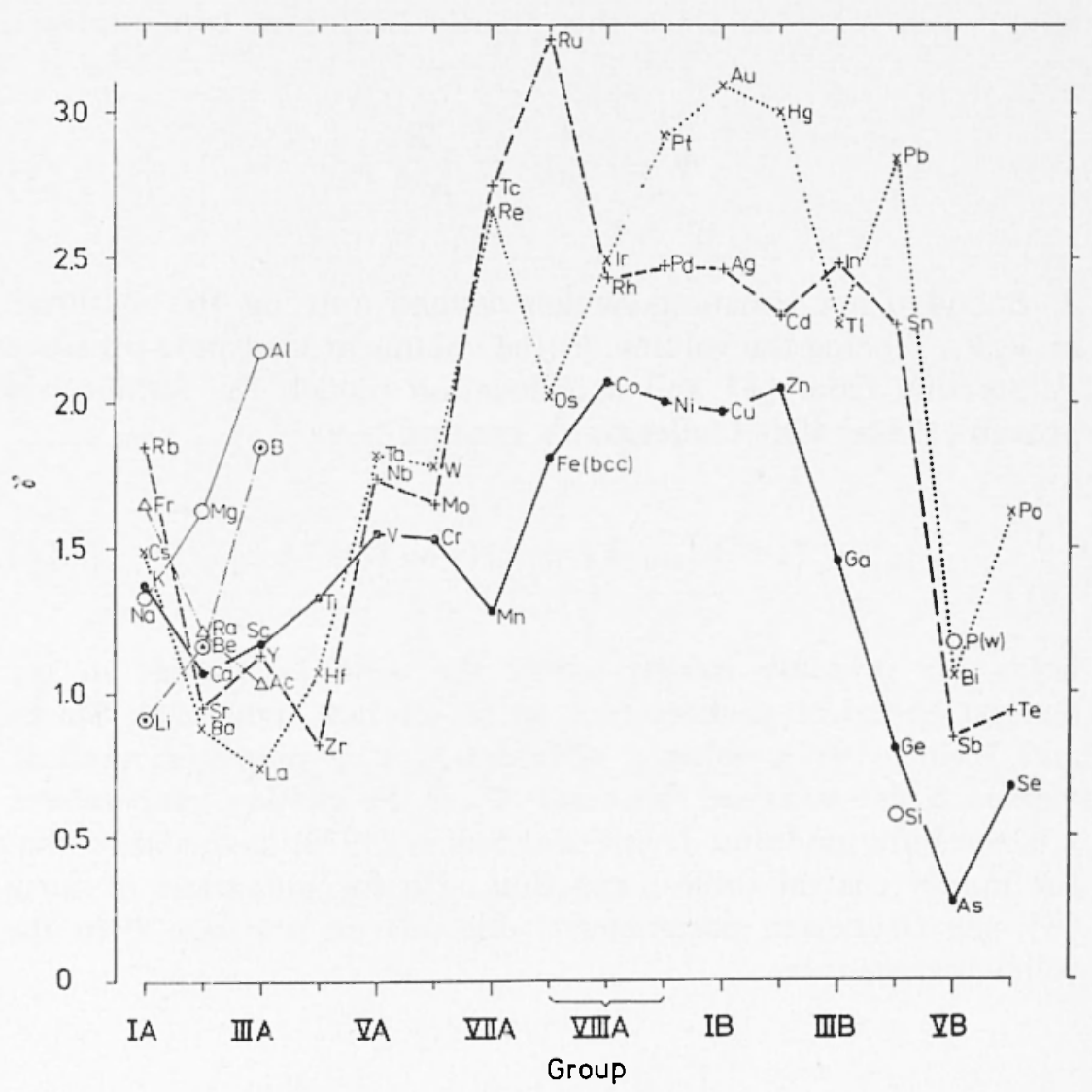

Fig. 6 - Grüneisen ratio $\gamma$ calculated from the lattice contribution to the heat capacity at constant volume, after Gschneidner's (1964) Table XXIV, plotted in the Periodic Table. 
et al. (1979) that the behaviour of the melting temperature in the outer core considerably depends on the interatomic potential assumed. In the following, we assume the Lennard-Jones potential. This is a rough but realistic approximation. The author has shown in another study (Walzer, 1982b) that another, more complicated expression for the potential arrived at by means of quantum mechanics reveals the best agreements with experimental data for metals, halides and some oxides. However, a Lennard-Jones potential can be used as a rough first approximation, even more so since this greatly facilitates computation:

$$
\text { () }=\frac{A}{x^{21 / 3}}-\frac{B}{r^{1 / 3}}
$$

$A, B$ and $n$ are constants which depend only on the material. $x=V / V_{\mathrm{o}}, V$ being the volume, $V_{\mathrm{o}}$ the volume at vanishing pressure $P$. Starting from [5] and a dislocation model, the author has proven (1982a) that Lindemann's melting law

$$
T_{m}{ }^{-1} \mathrm{~d} T_{m} / \mathrm{d} P=2(\gamma-1 / 3) / \%
$$

holds for pressure ranges where the solid is present in the densest spherical packing (i.e., in fcc or hcp structure). Stacey and Irvine (1977), using a different, i. e. a thermo-dynamical, approach also achieved this result. $T_{m}$ is the melting temperature, $x$ is the bulk modulus. Irvine and Stacey (1975) have shown that for purely central forces, and thus also for potentials of form [5], the Grüneisen parameter $\gamma$ depends on pressure $P$ in the following manner:

$$
\gamma=\frac{-\frac{1}{2} \frac{\mathrm{d} x}{\mathrm{~d} P}-\frac{5}{6}+\frac{2}{9} \frac{P}{\%}}{1-\frac{4}{3} \frac{D}{\%}}
$$


This formula had already been deduced in a completely different way from the free volume theory by Vashchenko and Zubarev (1963). Using a simple method that has already been employed by Kittel (1953), we deduce the equation of state belonging to [5]. From [5] we obtain

$$
\begin{gathered}
P=-\frac{\partial \Phi}{\partial x}=\frac{2 n}{3} \frac{A}{x^{2 n / 3+1}}-\frac{n}{3} \frac{B}{x^{n / 3+1}} \\
\%=-x \frac{\partial P}{\partial x}=\frac{2 n}{3}\left(\frac{2 n}{3}+1\right) \frac{A}{x^{2 n / 3+1}}+ \\
\left.-\frac{n}{3} ! \frac{n}{3}+1\right) \frac{B}{x^{n / 3+1}}
\end{gathered}
$$

as well as

$$
\begin{gathered}
-x \frac{\partial \varkappa}{\partial x}=\frac{2 n}{3}\left(\frac{2 n}{3}+1\right)^{2} \frac{A}{x^{2 n / 3+1}}+ \\
-\frac{i i}{3}\left(\frac{n}{3}+1\right)^{2} \frac{B}{x^{n / 3+1}} .
\end{gathered}
$$

If we note that $\frac{\partial x}{\partial P}=-x \frac{\partial \psi}{\partial x} \cdot \frac{1}{\psi}$

$$
\begin{aligned}
& \text { and if we use } \varkappa_{0}=\left.\right|_{x=1} \\
& \text { and } x_{1}=\partial \% /\left.\partial P\right|_{x=1}
\end{aligned}
$$

the costants $A, B, n$ can be expressed through $\chi_{0}$ and $\chi_{1}$ with the help of [8], [9] and [10]. This is very advantageous, because the latter quantities are macroscopically observable. In this 
way, using a different approach, we obtain from [8] the equation of state Ml by Ullmann and Pan'kov (1976)

$$
P=-\frac{3 \psi_{0}}{2-x_{1}} x^{\frac{1}{3}-\frac{2}{3} x_{1}}-x^{-\frac{1}{3}-\frac{1}{3} x_{1}}
$$

We now use the compatible formulas [6], [7] and [11] for an examination of the pressure dependence of the dimensionless quantities $Q_{n}$ and $N_{1}$.

From formula [1] it follows that

$$
\frac{R_{0}}{F} \frac{\partial N_{1}}{\partial P}=\frac{1}{T_{m} \rho} \frac{\partial x}{\partial P}-\frac{x}{T_{m}^{2} \rho} \frac{\partial T_{m}}{\partial P}-\frac{\varkappa}{T_{m} \rho^{2}} \frac{\partial \rho}{\partial P},
$$

which is reformulated by means of Lindemann's law into

$$
\frac{\partial \ln N_{1}}{\partial P}=\left[\frac{\partial x}{\partial P}-2\left(\gamma-\frac{1}{3}\right)-\frac{\varkappa}{\rho} \frac{\partial \rho}{\partial P}\right] i \%
$$

$Y$ can be eliminated by formula [7]. Furthermore, we note that $\frac{\partial \rho}{\partial P}=\frac{\rho}{x}$. Thus, we obtain from [13]

$$
\frac{\partial \ln N_{1}}{\partial P}=\frac{1-\frac{P}{x} \frac{\partial x}{\partial P}}{\frac{3}{4} x-P}
$$


Through similar computations we obtain from Vashchenko's and Zubarev's (1963) formula [7]

$$
\frac{\partial \ln \gamma}{\partial P}=\frac{\frac{\partial^{2} \psi}{\partial P^{2}}+\frac{4}{9}\left(\frac{1}{\psi}-\frac{P}{\chi^{2}} \frac{\partial x}{\partial P}\right)}{\frac{\partial x}{\partial P}-\frac{5}{3}+\frac{4}{9} \frac{P}{\psi}}+\frac{\frac{4}{9}\left(\frac{1}{\psi}-\frac{P}{\chi^{2}} \frac{\partial x}{\partial P}\right)}{\frac{1}{3}-\frac{4}{9} \frac{P}{\psi}} .
$$

From equations [1], [4] and [14] we obtain

$$
q_{n} \equiv \frac{\partial \ln Q_{n}}{\partial P}=\frac{\frac{P}{\psi} \frac{\partial \psi}{\partial P}-1}{\frac{3}{4} \psi_{n}-P}+n \frac{\partial \ln \gamma}{\partial P} .
$$

If [15] is substituted in [16], we obtain a formula by means of which it is principally possible to determine $Q_{n}=Q_{n}(P)$ by integration. So far, no use has been made of the specially chosen equation of state [11]. One mathematical difficulty arises because of the fact that the Ullmann-Pan'kov equation of state (like its special case, the Birch equation of state) cannot be analytically transformed from $P=P(x)$ to $x=x(P)$. This difficulty has been eluded by the following transformations

$$
\begin{gathered}
\frac{\partial \ln Q_{0}}{\partial P}=\frac{\frac{P(x)}{\psi(x)} \frac{\partial x}{\partial \psi}\left[\frac{\delta x}{\partial x}\right]^{-1}-1}{\frac{3}{4} \psi(x)-P(x)}, \\
\varkappa_{0}=-x \partial P / \partial x, \\
\frac{\partial \psi}{\partial P}=-\frac{x}{\psi} \frac{\partial \psi}{\partial x}
\end{gathered}
$$



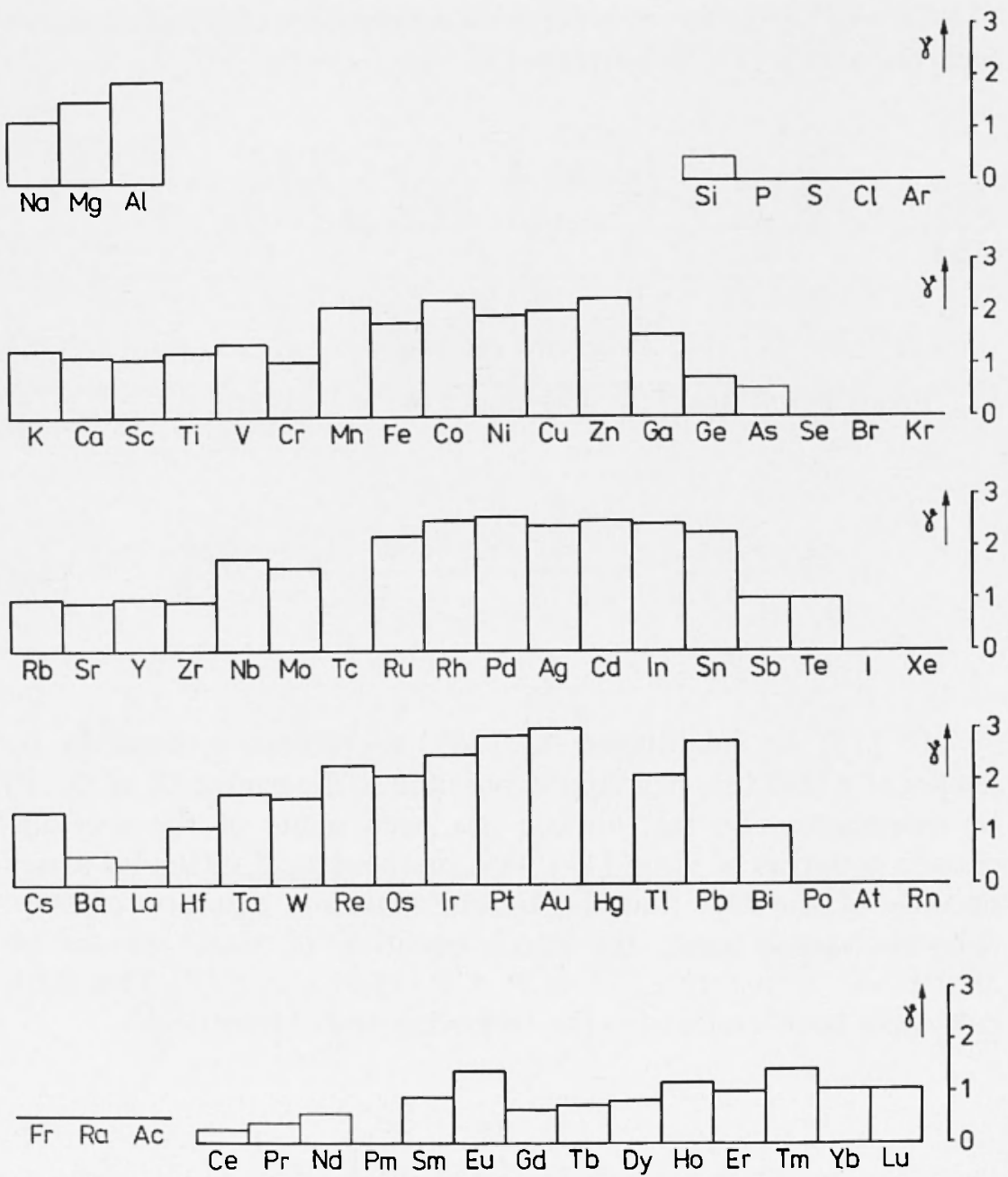

Fig. 7 - Grüneisen ratio $\gamma$ after values given by Guinan and and Steinberg (1974), plotted in the Periodic Table. This means in cases where the column has a disappearing height that no numerical value is known.

$$
\frac{\partial^{2} x}{\partial P^{2}}=\left(\frac{\partial P}{\partial x}\right)^{-2}\left(\frac{\partial^{2} x}{\partial x^{2}}-\frac{\partial x}{\partial x} \frac{\partial^{2} P / \partial x^{2}}{\partial P / \partial x}\right) .
$$


In the auxiliary function $q_{n}$ defined by [16] we eliminate $P, x, \partial x / \partial P$ and $\partial^{2} x / P^{2}$ through the equations [11], [15] and [17] to [20]. Thus, $q_{n}$ is known as a function of $x$. The equation of state effects that $P$-values bi-uniquely correspond to the $x$-values. Using a computer, we calculated $Q_{n}$ as a function of pressure $P$ by means of numerical integration of [16].

\section{The systematics of the quantities $Q_{n}$ in the Periodic table}

To study the distribution of the dimensionless quantity $Q_{1}$ (i.e., $Q_{n}$ for $n=1$ ), we plotted this quantity in Fig. 8 against the groups of the Periodic Table. Using the formulas of the previous section; we computed $Q_{1}$ for the pressure at the core-mantle boundary (CMB) for the chemical elements and plotted it in Fig. 9 against the groups. Fig. 10 shows the corresponding distribution for the pressure at the inner-core boundary (ICB). A comparison of these three Figures shows that the change seen in the characteristic curves is less considerable for the outer core than for the mantle. The naterial parameters required for the computation have been listed in Tab. 1, their origin is given in the legend of the Table. In Figures 11 to 13, the quantities $Q$, have been plotted as a function of pressure. Generally, no strong concentration of the curves can be found for the elements of periods 4 to 6 . It is particularly apparent for the 5th and 6th periods that the elements with the densest spherical packing (i. e., those present in hcp or fcc structure) are predominant in the upper curves. Much more favourable results are obtained for the dimensionless quantity $Q_{0}$ which is plotted against the pressure in Fig. 14 for the 4th period, in Fig. 15 for the 5th period and in Fig. 16 for the 6th period. In Fig. 14, all fcc and hcp materials arc found in the strong middle bundle. Only the element Sc does not fit in this scheme. In Fig. 15, the same result is found for the elements of the 5th period. With the exception of $\mathrm{Y}$ and $\mathrm{Sr}$, all elements with fcc or hcp lattices are found in the strong middle bundle of curves. Two clearly separated curve bundles can also be seen for the elements of the 6th period in Fig. 16. Except Hf and Re, all elements with fcc and hop structures 


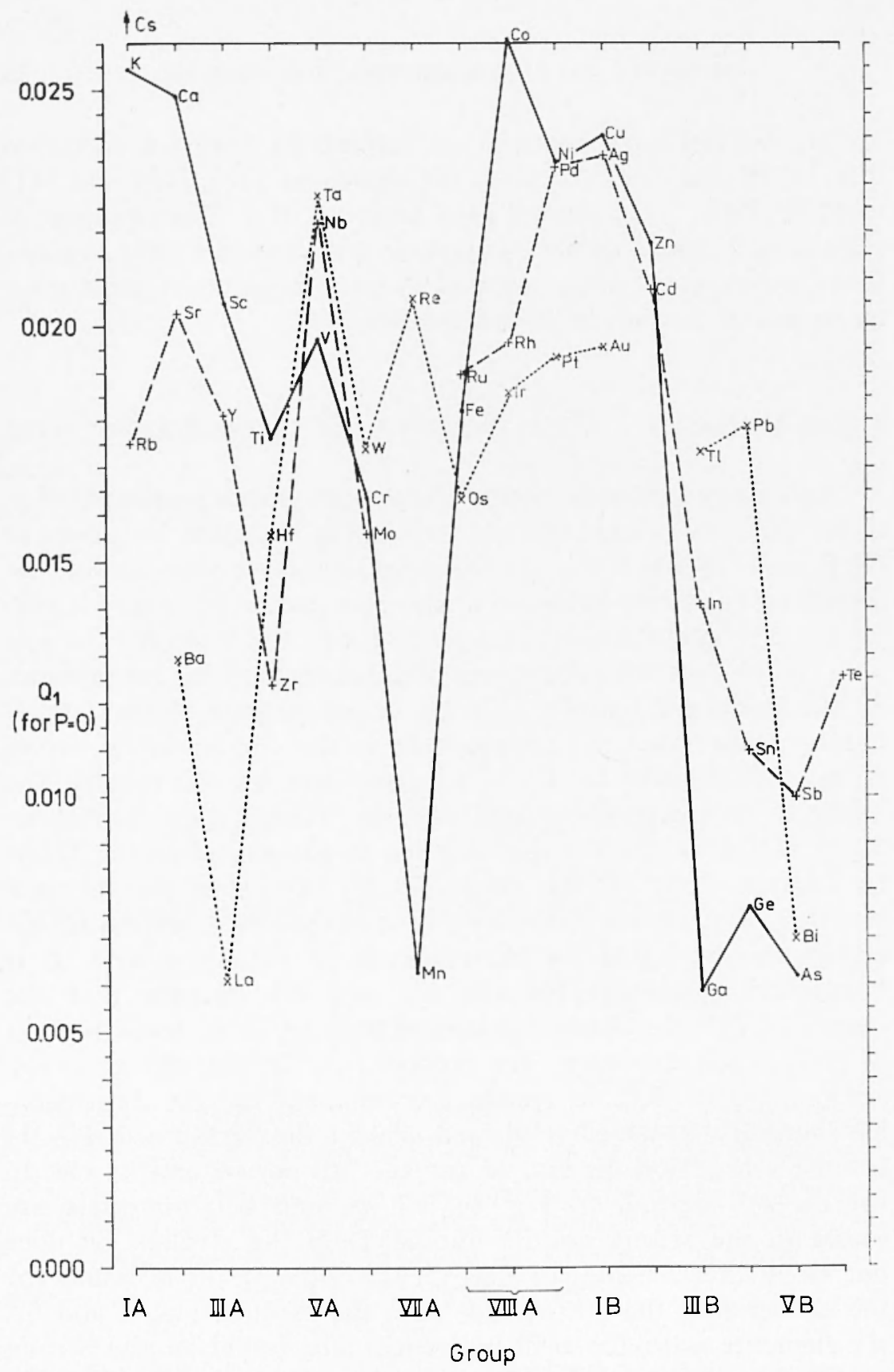

Fig. 8 - Plot of the dimensionless quantity $Q_{1}$ in the Periodic Table for the elements of the 4th peried (continuous line), 5 th period (dotted line) and $6 \mathrm{th}$ period (point line) at pressure $\mathbf{P}=0$. 
are found in the lower narrow bundle of curves, while the bcc structure is predominant in the upper bundle. Since, if the temperatures were lower, one would have to reckon with the densest spherical packings for the pressures existing in the outer core, the fcc-hcp bundles of $Q_{o}$ provide a possibility for estimating the quotient $T_{m} / F$ for the outer core without becoming too specific in regard of the chemical composition. In Fig. 17, $Q_{o}$ has been plotted against the groups of the Periodic Table, the pressure being $P=1354$ kbars. These characteristics do not significantly vary for the higher pressures existing in the interior of the outer core. The characteristic curves of $Q_{o}$ at $P=P_{\text {CMB }}$ reveal a slight similarity to the Leibfried number $L$, the modified Leibfried number $L^{\prime}$, and the Bragg number $B$, as can be seen from a comparison of Fig. 17 with Figs. 18 to 20. However, these quantities are given for zero pressure. The Figures were plotted according to the numerical values given by Gschneidner (1964). As defined in the paper by Leibfried (1950), the Leibfried number is

$$
L=\frac{R_{\mathrm{u}} T_{\mathrm{mn}}}{\mu \nu},
$$

where $v$ is the atomic volume and $\ell$ the shear modulus. This quantity was modified by Gschneidner (1964):

$$
L^{\prime}=\frac{K T_{m}}{\mu v}
$$

In this modified Leibfried number, $K$ is a constant which, however, has a different value for each crystal structure, while

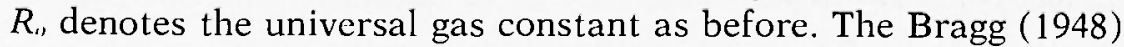
number, on the other hand, is defined by

$$
B=\frac{\wedge \underline{H}}{\| v}
$$




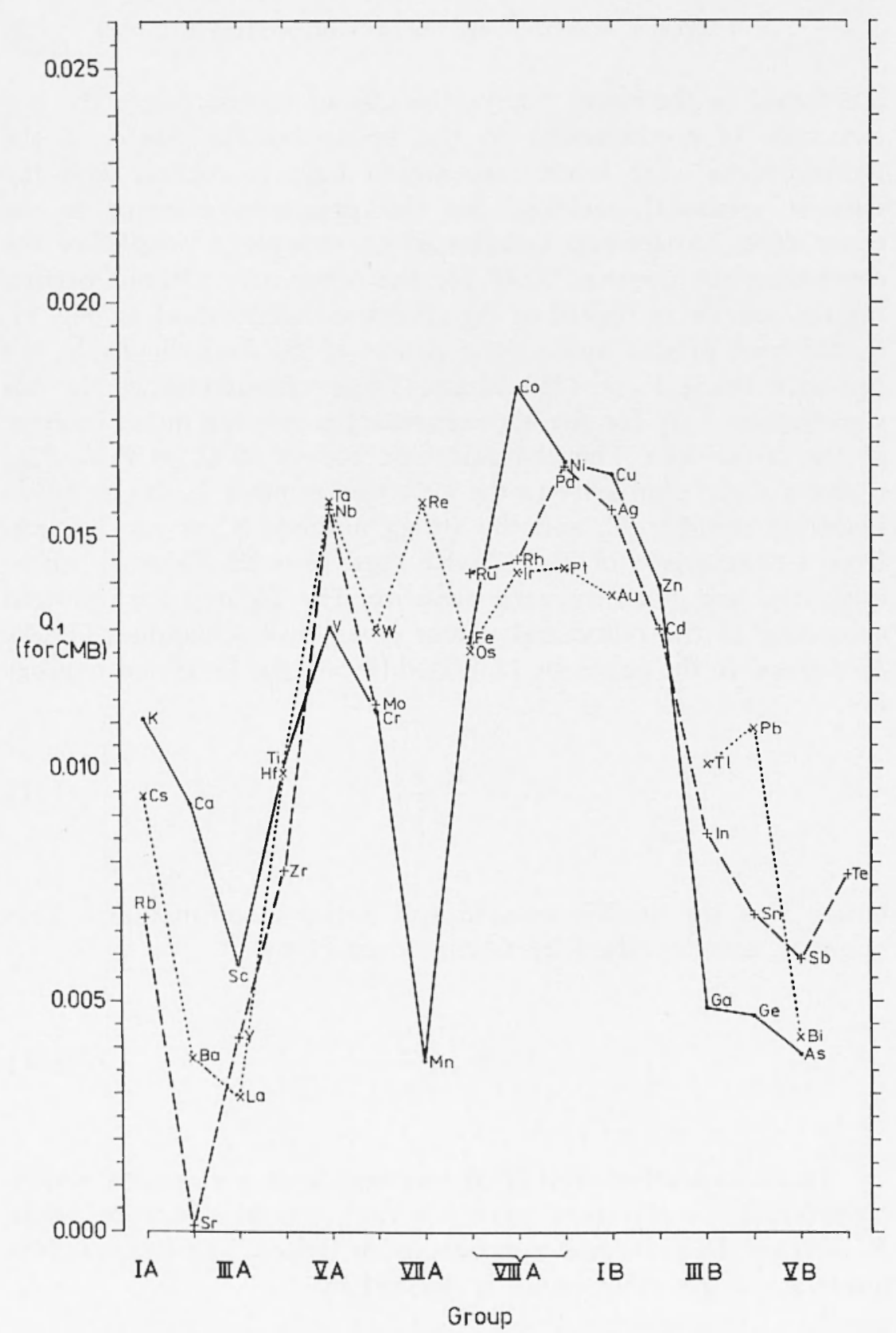

Fig. 9 - Plot of the quantity $\mathrm{Q}_{1}$ in the Periodic Table at the pressure existing at the core-mantle boundary. Designations as in Fig. 8. 


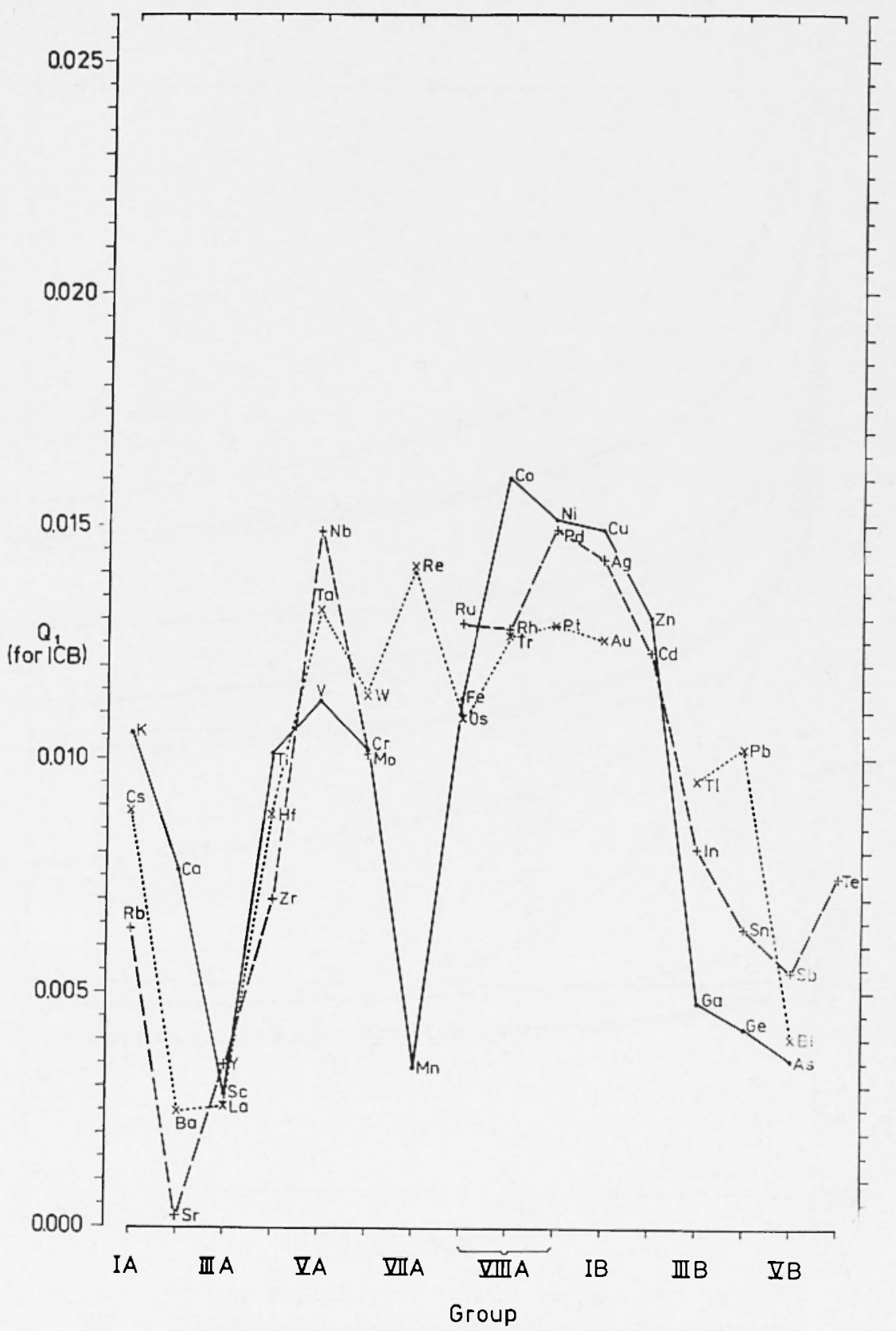

Fig. 10 - Plot of the quantity $\mathrm{Q}_{1}$ in the Periodic Table at the pressure existing at the inner-core boundary. Design. ations as in Fig. 8. 


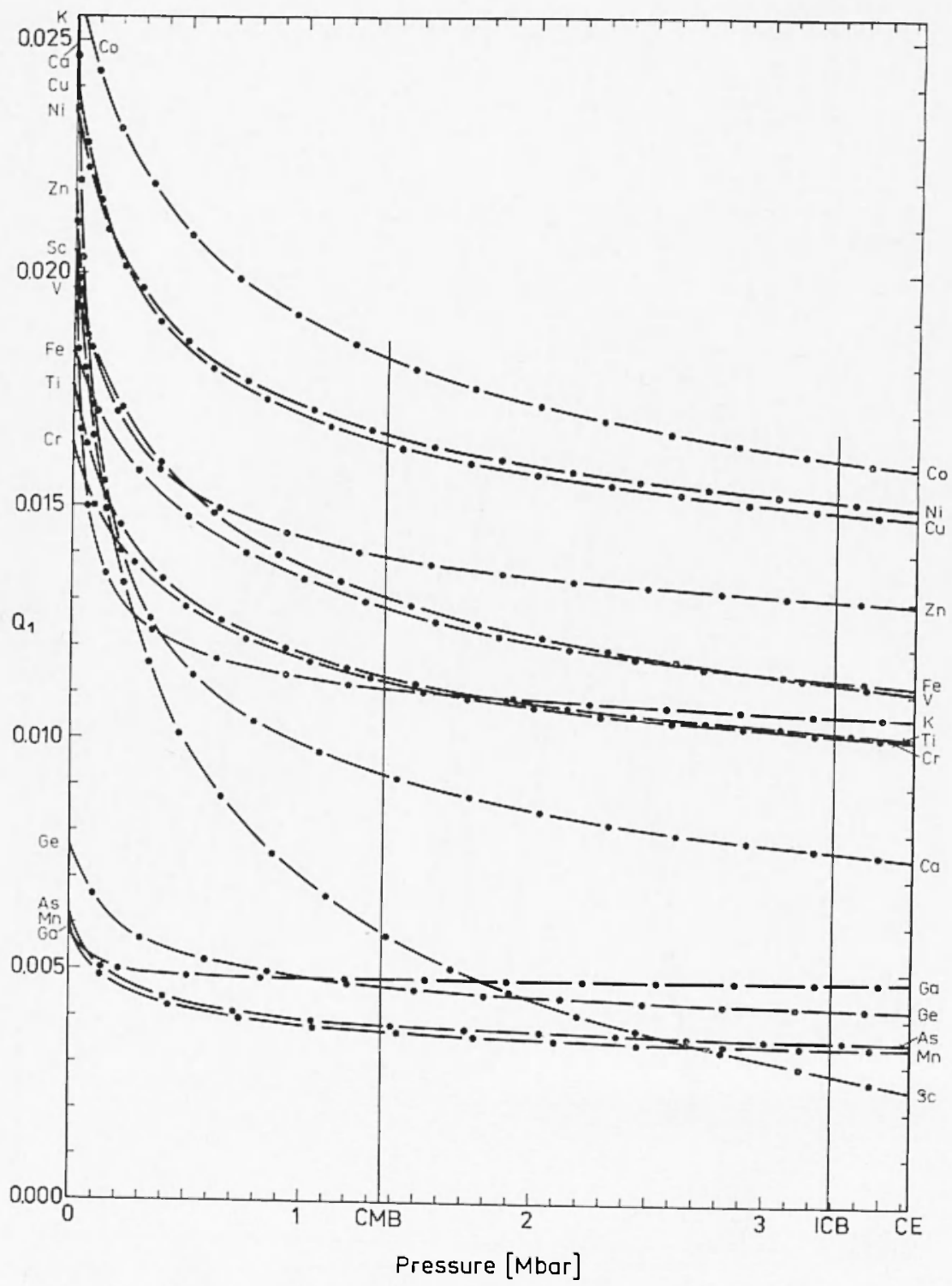

Fig. 11 - Dependence of the dimensionless quantity $Q_{1}$ on pressure for the chemical elements on pressure for the chemical elements of the 4 th period of the Periodic Table. 


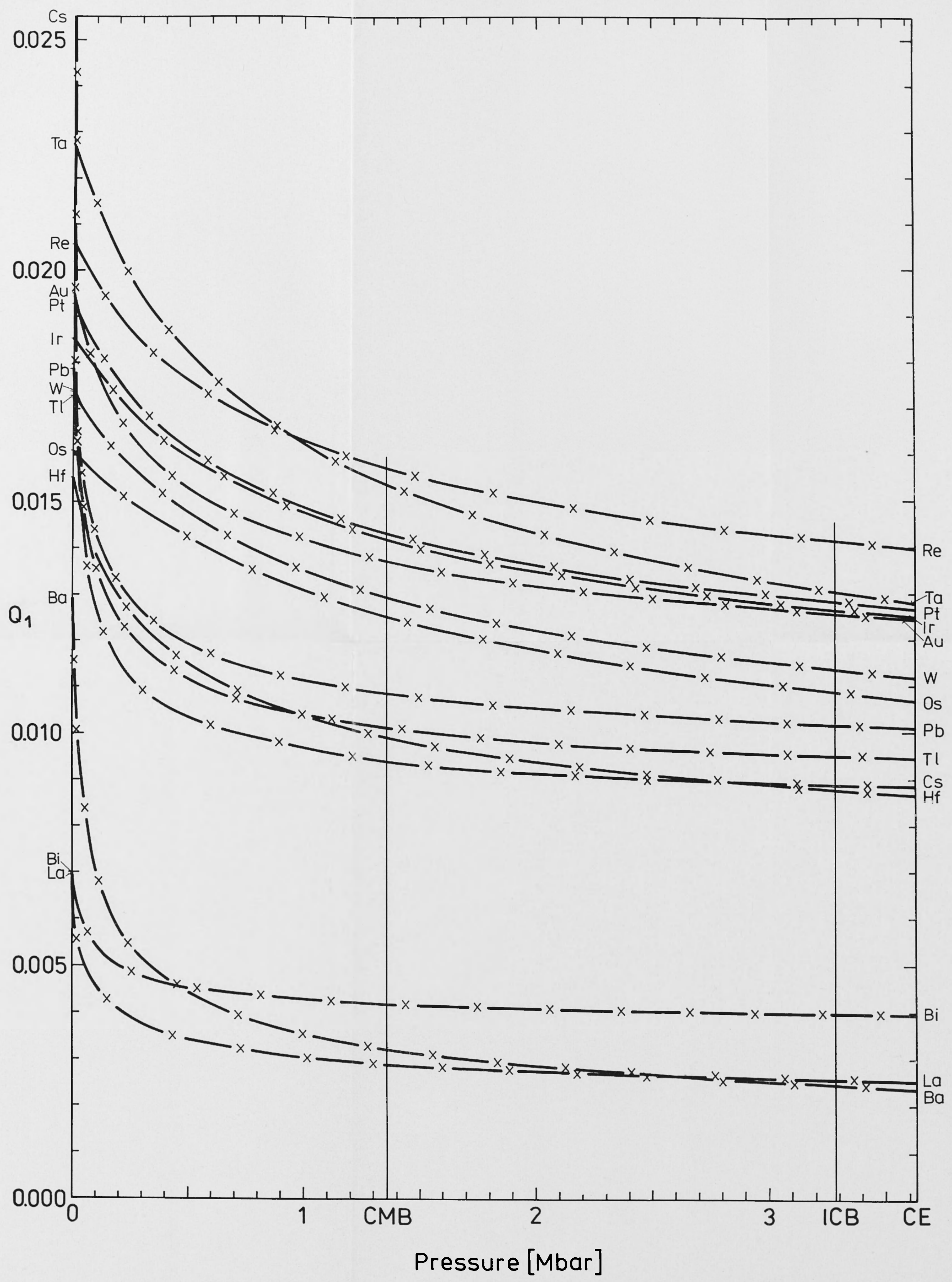




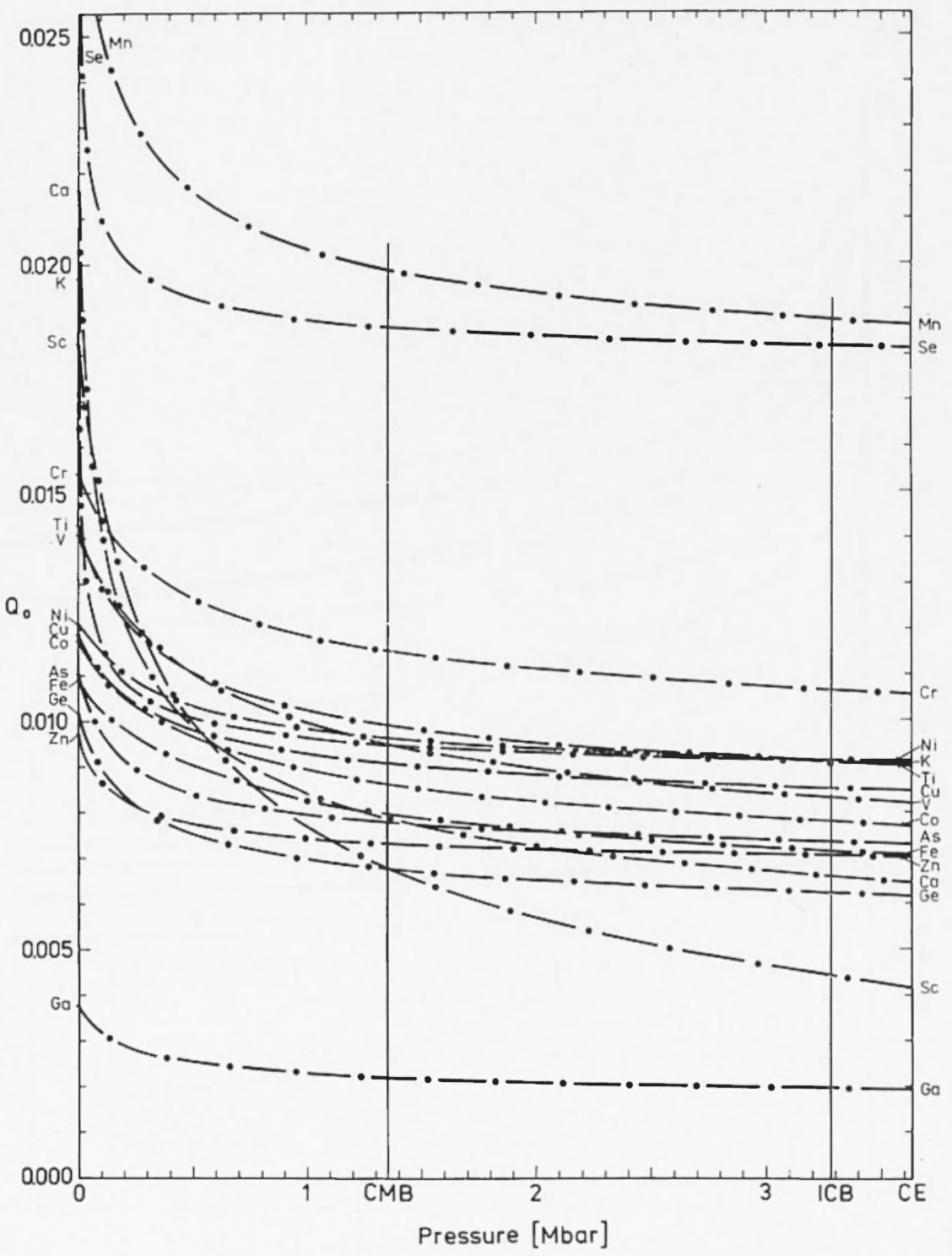

Fig. 14 - Dependence of the dimensionless quantity $\mathrm{O}_{0}$ on pressure for the chemical elements of the 4 th group of the: Periodic Table. A comparison with Fig. 11 reveals a significantly closer proximity of the curves. 


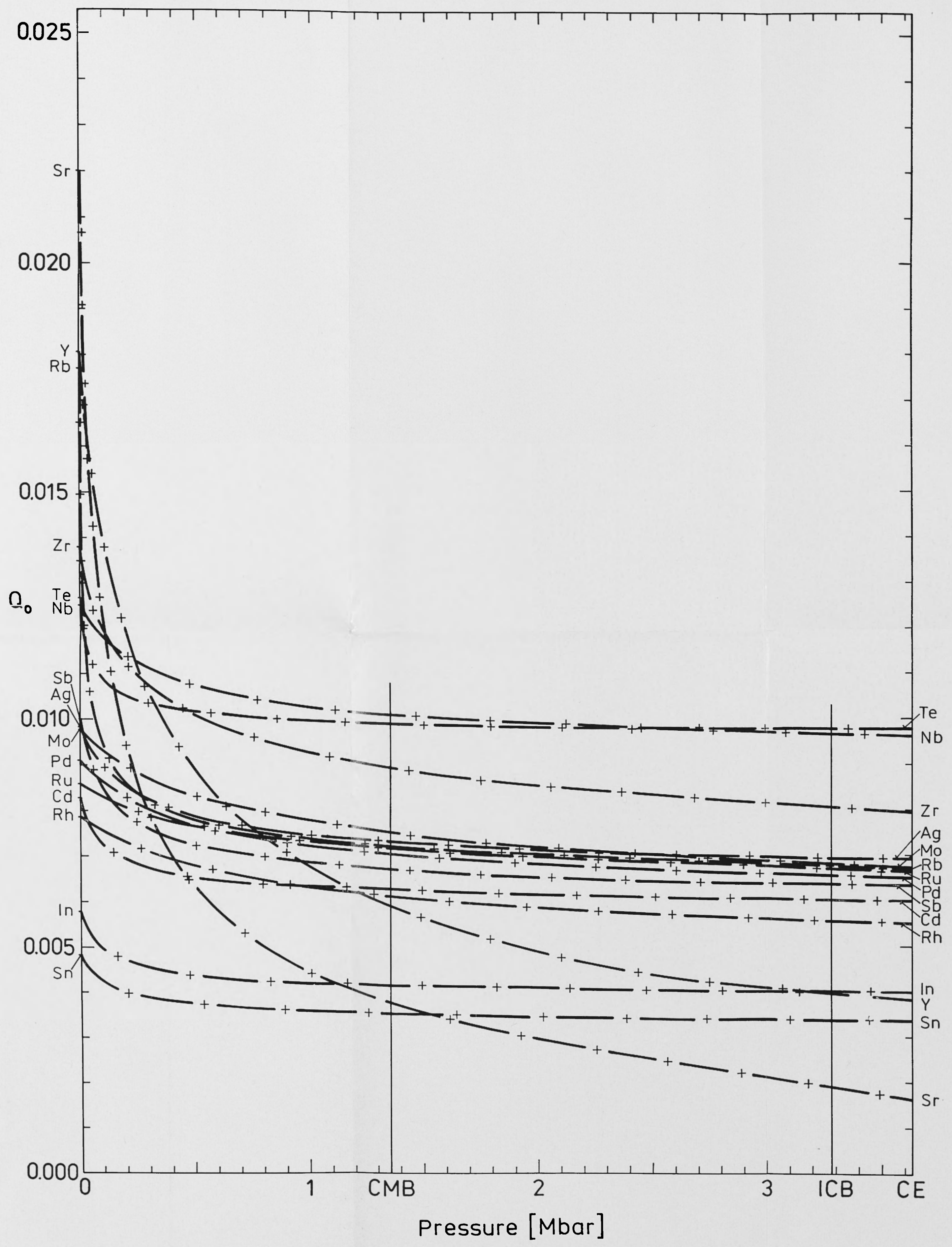

Fig. 15 - Pressure dependence of the quantity $Q_{0}$ for the elements of the 5 th period. 


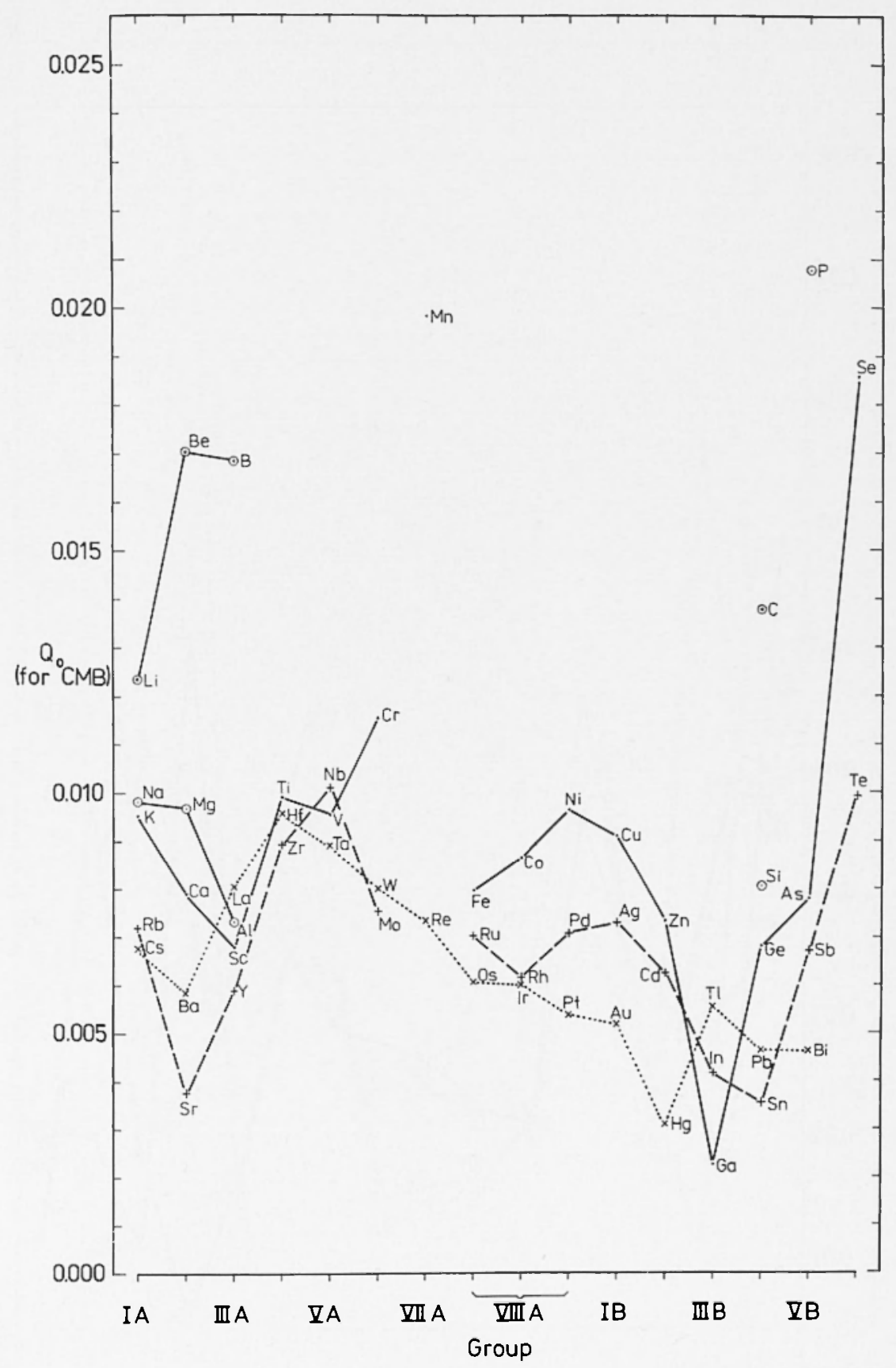

Fig. 17 - The dimensionless quantity $Q_{0}$ subjected to the pressure existing at the core-mantle boundary (CMB). Representation in the Periodic Table for the elements of the $4 \mathrm{th}$ period (continuous line), 5th period (dotted line) and 6 th period (point lint). 


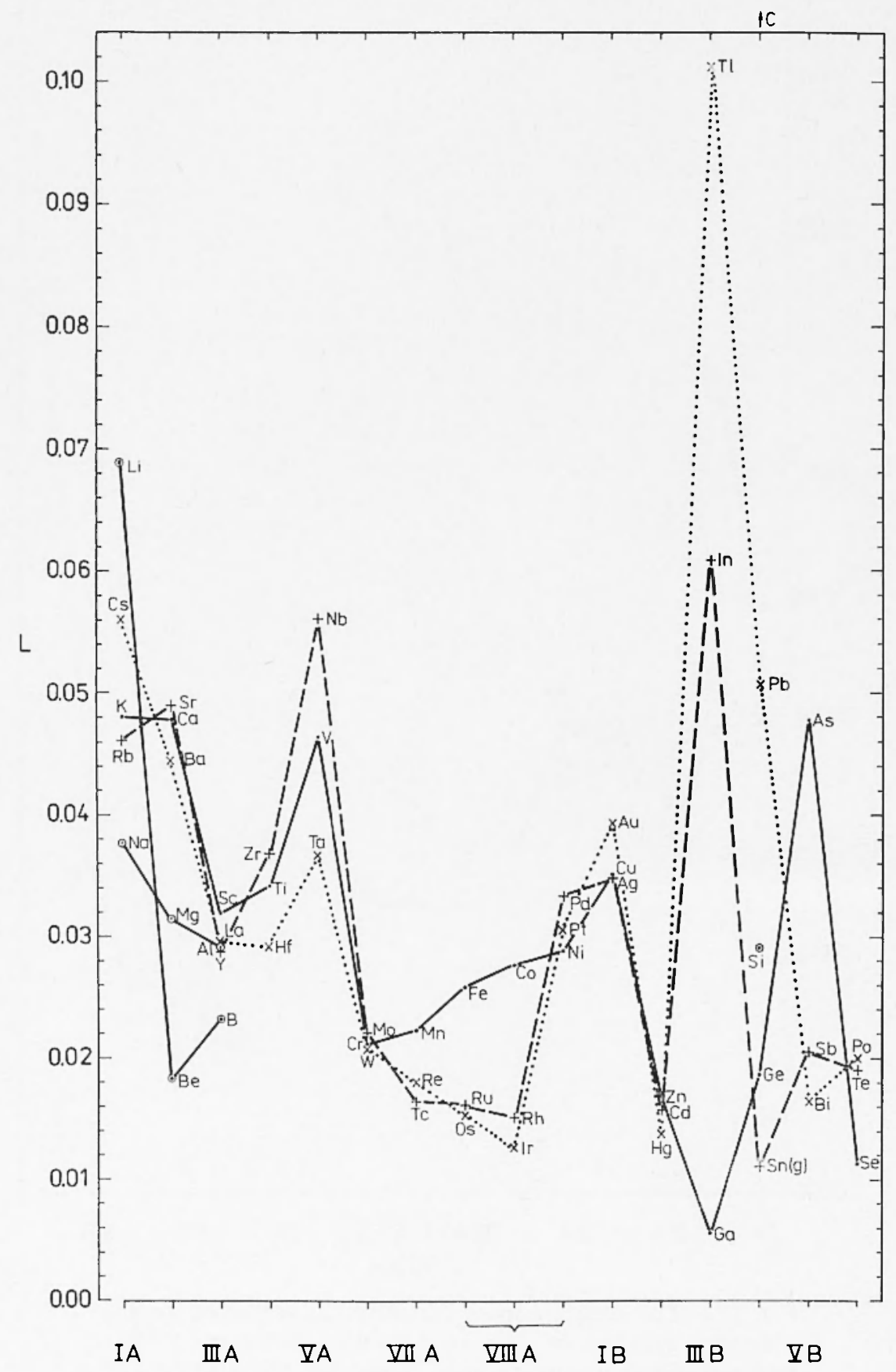

Fig. 18 - The Leibfried number $\mathrm{L}$, plotted in the Periodic Table for zero pressure. Designations as in Fig. 17. 


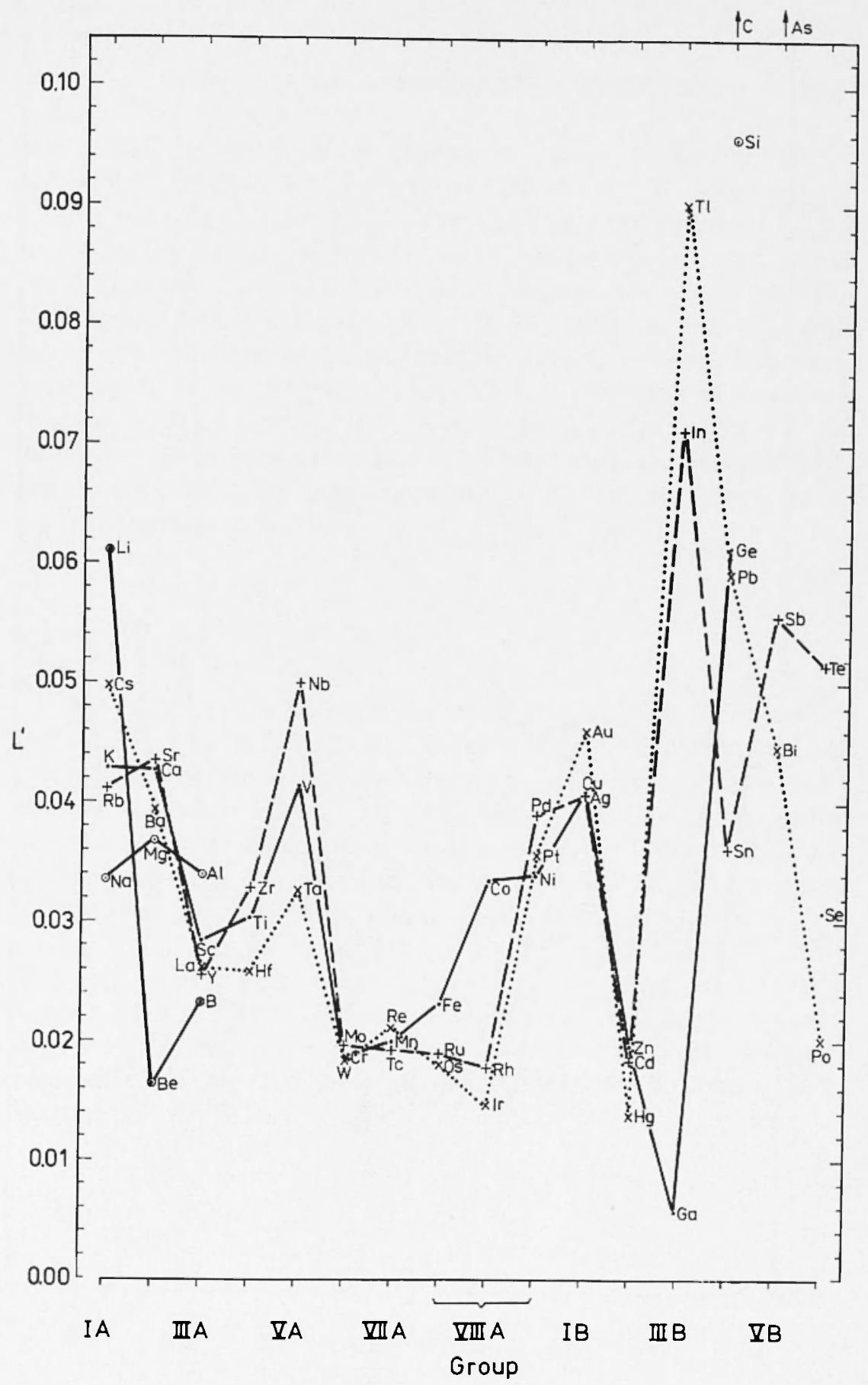

Fig. 19 - The modified Leibfried number L', plotted in the the Periodic Table for zero pressure. Designations as in Fig. 17. 


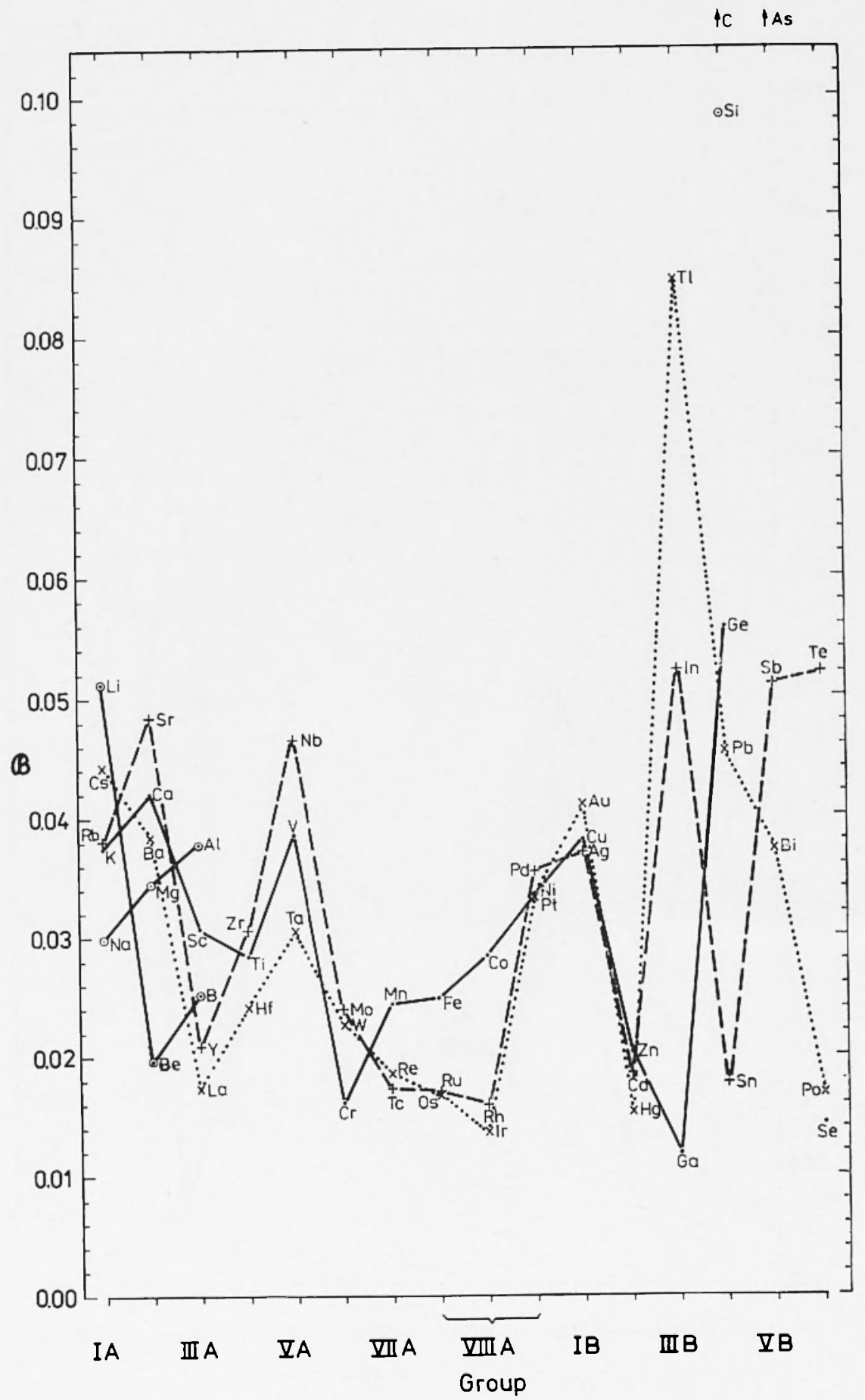

Fig. 20 - The Bragg number, plotted in the Periodic Table for zero pressure. Designations as in Fig. 17. 
where $\Delta \mathrm{H}$ is the heat of fusion. In view of Richard's rule $\Delta H \sim R_{0} T_{m}$ is does not surprise that $L$. $L^{\prime}$ and $B$, when plotted in the Periodic Table, yield very similar characteristic curves (cf. Figs. 18 to 20). However, these quantities are not suited for estimating $T_{m}$ in the outer core, because the shear modulus $\mu$ disappears in the liquid state. In contrast to this the bulk modulus $x$ does not vary considerably during melting. Therefore, $Q_{u}$ appears to be a quantity useful for geophysical purposes. It goes without saying that the pressure dependence of the individual quantities must be taken into account. Thus, Fig. 17 shows a comparable representation of $Q_{0}$ for the pressure at the core-mantle boundary.

\section{CONCLUSIONS}

A systematic correlation between the melting temperature and other physical quantities has been found. In particular, two new, dimensionless quantities, $Q_{t}$ and $Q_{o}$, depending on $T_{m}$, were investigated with respect to their dependence on pressure as well as to their distribution in the Periodic Table. While the $Q$, for pressures in the Mbar range strongly differ from one another for the individual chemical elements, it was found for $Q_{u}$ that the curves of materials having the same lattice structure prior to melting run very close to one another. The results suggest that it should be possible even without detailed knowledge of the chemical composition of the outer core to determine the melting temperature to formula weight ratio as a function of depth. 
TABLE I

See caption at page 34 .

\begin{tabular}{|c|c|c|c|c|c|c|}
\hline $\begin{array}{l}\text { E.la- } \\
\text { ment }\end{array}$ & $T_{m}[K]$ & $\rho\left[\mathrm{g} / \mathrm{cm}^{3}\right]$ & $\%_{0}[$ kbar $]$ & $F[\mathrm{~kg} / \mathrm{mol}]$ & $N_{1}$ & $x_{1}$ \\
\hline $\mathrm{Li}$ & 454 & 0.534 & 115 & 6.94 & 39.59 & 3.56 \\
\hline $\mathrm{Be}$ & 1557 & 1.84 & 1100 & 9.01 & 41.61 & 4.6 \\
\hline $\mathrm{B}$ & 2498 & 2.31 & 1785 & 10.81 & 40.22 & 3.26 \\
\hline $\mathrm{Na}$ & 370.8 & 0.970 & 61.8 & 22.99 & 47.51 & 3.59 \\
\hline $\mathrm{Mg}$ & 923 & 1.74 & 344.2 & 24.31 & 62.66 & 4.16 \\
\hline $\mathrm{Al}$ & 933.2 & 2.697 & 729.1 & 26.98 & 94.00 & 4.7 \\
\hline $\mathrm{Si}$ & 1685 & 2.33 & 970.8 & 28.09 & 83.54 & 4.16 \\
\hline$P(r)$ & 868 & 2.35 & 192 & 30.97 & 35.06 & 6.68 \\
\hline K & 336.6 & 0.86 & 31.2 & 39.10 & 50.69 & 3.85 \\
\hline $\mathrm{Ca}$ & 1112 & 1.53 & 163 & 40.08 & 46.18 & 2.7 \\
\hline $\mathrm{Sc}$ & 1812 & 2.98 & 546 & 44.96 & 54.68 & 2.1 \\
\hline $\mathrm{Ti}$ & 1941 & 4.50 & 1060 & 47.90 & 69.91 & 4.37 \\
\hline $\mathrm{Cr}$ & 2148 & 7.194 & 1600 & 52.00 & 64.76 & 4.89 \\
\hline V & 2178 & 6.09 & 1537 & 50.94 & 70.99 & 3.5 \\
\hline $\mathrm{Mn}$ & 1517 & 7.47 & 597 & 54.94 & 34.81 & 5.0 \\
\hline $\mathrm{Fe}(\varepsilon)$ & 1808 & 8.36 & 2060 & 55.85 & 91.55 & 4.0 \\
\hline Co & 1765 & 8.79 & 1860 & 58.93 & 84.98 & 4.26 \\
\hline $\mathrm{Ni}$ & 1726 & 8.90 & 1790 & 58.71 & 82.28 & 6.20 \\
\hline $\mathrm{Cu}$ & 1356 & 8.932 & 1330 & 63.55 & 83.93 & 5.65 \\
\hline $\mathrm{Zn}$ & 692.655 & 7.14 & 647 & 65.37 & 102.86 & 6.40 \\
\hline $\mathrm{Ga}$ & 302.8 & 5.91 & 568 & 69.72 & 266.15 & 3.6 \\
\hline $\mathrm{Ge}$ & 1209 & 5.33 & 724.3 & 72.59 & 98.13 & 4.35 \\
\hline As & 1090 & 5.77 & 631 & 74.92 & 90.40 & 5.2 \\
\hline $\mathrm{Se}$ & 490 & 4.81 & 89.7 & 78.96 & 36.14 & 5.8 \\
\hline $\mathrm{Rb}$ & 311.8 & 1.53 & 26.2 & 85.47 & 56.46 & 3.39 \\
\hline $\mathrm{Sr}$ & 1045 & 2.58 & 116.1 & 87.62 & 45.38 & 2.1 \\
\hline Y & 1775 & 4.47 & 410 & 88.91 & 55.26 & 2.1 \\
\hline $\mathrm{Zr}$ & 2123 & 6.53 & 949 & 91.22 & 75.11 & 4.11 \\
\hline $\mathrm{Nb}$ & 2741 & 8.63 & 1690 & 92.91 & 79.84 & 6.9 \\
\hline Mo & 2888 & 10.218 & 2610 & 95.94 & 102.06 & 4.4 \\
\hline $\mathrm{Tc}$ & 2443 & & & 98.91 & & \\
\hline Ru & 2553 & 12.44 & 3030 & 101.07 & 115.97 & 6.61 \\
\hline $\mathrm{Rh}$ & 2233 & 12.42 & 2820 & 102.91 & 126.87 & 4.50 \\
\hline $\mathrm{Pd}$ & 1825 & 12.04 & 1880 & 106.4 & 109.49 & 5.35 \\
\hline $\mathrm{Ag}$ & 1234 & 10.50 & 1015 & 107.87 & 101.63 & 5.53 \\
\hline $\mathrm{Cd}$ & 594.18 & 8.65 & 457.9 & 112.40 & 120.44 & 6.77 \\
\hline
\end{tabular}


TABLE I (contintation)

\begin{tabular}{|c|c|c|c|c|c|c|}
\hline $\begin{array}{c}\text { Ele- } \\
\text { ment }\end{array}$ & $T_{m}[K]$ & $\rho\left[\mathrm{g} / \mathrm{cm}^{3}\right]$ & $x_{0}[$ kbar $]$ & $F[\mathrm{~kg} / \mathrm{mol}]$ & $N_{1}$ & $x_{1}$ \\
\hline In & 429.76 & 7.29 & 392 & 114.82 & 172.78 & 6.0 \\
\hline $\mathrm{Sn}$ & 505.06 & 7.28 & 532 & 118.69 & 206.55 & 6.01 \\
\hline $\mathrm{Sb}$ & 903.6 & 6.69 & 411 & 121.75 & 99.56 & 4.9 \\
\hline Te & 722.8 & 6.27 & 233 & 127.60 & 78.90 & 8.3 \\
\hline Cs & 301.8 & 1.83 & 17.9 & 132.91 & 51.81 & 3.17 \\
\hline $\mathrm{Ba}$ & 998 & 3.61 & 94.3 & 137.34 & 43.24 & 2.43 \\
\hline La & 1193 & 6.16 & 267 & 138.91 & 60.70 & 3.2 \\
\hline $\mathrm{Ce}$ & 1070 & 6.77 & 239 & 140.12 & 55.60 & \\
\hline $\operatorname{Pr}$ & 1208 & 6.78 & 306 & 140.10 & 62.95 & \\
\hline $\mathrm{Nd}$ & 1297 & 7.00 & 327 & 144.24 & 62.48 & \\
\hline $\mathrm{Pm}$ & 1308 & & & 141.91 & & \\
\hline $\mathrm{Sm}$ & 1345 & 7.54 & 294 & 150.4 & 52.44 & \\
\hline Eu & 1099 & 5.25 & 147 & 151.96 & 46.57 & \\
\hline $\mathrm{Gd}$ & 1585 & 7.89 & 383 & 157.25 & 57.92 & \\
\hline $\mathrm{Tb}$ & 1629 & 8.27 & 399 & 158.93 & 56.61 & \\
\hline Dy & 1680 & 8.53 & 384 & 162.50 & 52.37 & \\
\hline Ho & 1734 & 8.80 & 397 & 164.93 & 51.61 & \\
\hline $\mathrm{Er}$ & 1770 & 9.04 & 411 & 167.26 & 51.67 & \\
\hline $\mathrm{Tm}$ & 1818 & 9.32 & 397 & 168.93 & 47.61 & \\
\hline $\mathrm{Yb}$ & 1097 & 6.97 & 133 & 173.04 & 36.20 & \\
\hline Lu & 1925 & 9.84 & 411 & 179.97 & 46.97 & \\
\hline $\mathrm{Hf}$ & 2495 & 13.25 & 1080 & 178.49 & 70.13 & 3.95 \\
\hline $\mathrm{Ta}$ & 3271 & 16.62 & 1910 & 180.95 & 76.46 & 3.15 \\
\hline W & 3653 & 19.26 & 3060 & 183.85 & 96.17 & 3.95 \\
\hline $\operatorname{Re}$ & 3433 & 21.03 & 3587 & 186.2 & 111.27 & 5.41 \\
\hline Os & 3300 & 22.58 & 4200 & 190.2 & 128.94 & 3.4 \\
\hline Ir & 2716 & 22.65 & 3580 & 192.22 & 134.53 & 4.83 \\
\hline $\mathrm{Pt}$ & 2042 & 21.47 & 2770 & 195.09 & 148.25 & 5.18 \\
\hline $\mathrm{Au}$ & 1336.2 & 19.30 & 1664 & 196.97 & 152.86 & 6.51 \\
\hline $\mathrm{Hg}$ & 234.28 & 14.24 & 282 & 200.59 & 203.92 & 4.6 \\
\hline $\mathrm{T} 1$ & 576 & 11.85 & 337 & 204.37 & 121.37 & 5.1 \\
\hline $\mathrm{Pb}$ & 600.576 & 11.34 & 419 & 207.2 & 153.31 & 5.72 \\
\hline $\mathrm{Bi}$ & 544.525 & 9.807 & 332 & 208.98 & 156.26 & 6.06 \\
\hline Th & 2024 & 11.72 & 543 & 232.04 & 63.88 & \\
\hline U & 1404 & 19.05 & 987 & 238.03 & 105.65 & \\
\hline
\end{tabular}


TABLE I - Physical constants of chemical elements used for $P=0$. Melting temperature $T_{m}$ according to Gschneidner (1964), formula weight $F$ according to Ebert (1976), density $p$ and bulk modulus $x$ for the lanthanons and actinons according to Kittel (1973), density, bulk modulus and its derivative with respect to pressure for the other elements according to Ullmann and Pan'kov (1976). $N_{1}$ is the dimensionless quantity for $P=0$ defined by Eq. [1], where $R_{\mathrm{o}}=8.31441 \mathrm{~J} /(\mathrm{K} \cdot \mathrm{mol})$. The value denoted by a) actually applies to bcc iron, if the hypothetical melting point curve for hcp iron by Liu (1975) is drawn for low pressures, one attains the same value. The Grüneisen parameters $\gamma$ used are not listed in the Table. The values given by Guinan and Steinberg (1974) were used. Only for $\mathrm{Fe}$, the value $\gamma=1.67$ according to Plendl (1973) was preferred. 


\section{REFERENCES}

Anderson O.L., Mulargia F., 1977 - A critique of theories on the Grineisen parameter. Preprint.

Boschi E., Mulargia F., Bonafede M., 1979 - "Geophys. J. R. astr. Soc. ", $58,201$.

Bragc L., 1948 - "Symposiumn on Internal Stresses ", Inst. Metals, London, p. 221.

Dziewonski A.M., Hales A.L., Lapwood E.R., 1975 - « Phys. Earth Planet. Inter. " $10,12$.

EBERT H. (Editor), 1976 - Physikalisches Taschenbuch. Vieweg, Braunschweig, $617 \mathrm{pp}$.

Gscinneidner K.A. Jr., 1964 - "Solid State Physics ». 16, 275.

Guinan M.W., Steinberg D.J., 1974 - « J. Phys. and Chem. Solids ", 35, 1501.

Irvine R.D., Stacey F.D., 1975 - "Phys. Earth Planet. Interiors », 11, 157.

Kittel C., 1953 - Introducton to Solid State Physics. John Wiley and Sons Inc., New York.

KitTel C., 1973 - Einfïhrung in die Festkörperphysik. Oldenbourg, München.

Leibried G., 1950 - «Z. Physik », 127, 344.

LiU L.-G., 1975 - « Geophys. J.R. astr. Soc. », 43, 697.

Plende J.N., 1973 - “ phys. stat. sol. " (b), 57, 187.

Plendl J.N., 1974 - " phys, stat. sol." (b), 63, 519.

Plendl J.N., Gielisse, P.J.M., 1969 - Compressibility and Polymorphism of Solids. "AFCRL-69-0429, Phys. Sci. Res. Papers », No. 395.

Plindi, J.N., Gielisse P.J., 1970 - « phys. stat. sol. ", 42, 681.

Plendl, J.N., Gielisse P.J., 1972 - « phys. stat. sol. "(b), 53, 457.

Stacey F.D., Irvine R.D., 1977 - "Aust. J. Phys. ", 30, 613. 
Ulimann W., Pan'kov V.L., 1976 - "Veröff. Zentralinst. Physik der Erde", $41,1$.

Vasichenko V.Ya., Zubarev V.N., 1963 - «Sov. Phys. Solid State », 5, 653.

WALzER U., 1982a - Volume Dependence of Melting Temperature at High Pressure and its Relation to a New Dimensionless Quantity. "Exper. Technik der Physik", in press.

Walzer U., 1982b - A New Equation of State for High Compression. "Phys. Earth Planet. Interiors ", in press. 